\title{
Case study of wave breaking with high-resolution turbulence measurements with LITOS and WRF simulations
}

\author{
Andreas Schneider ${ }^{1, a}$, Johannes Wagner ${ }^{2}$, Jens Söder ${ }^{1}$, Michael Gerding ${ }^{1}$, and Franz-Josef Lübken ${ }^{1}$ \\ ${ }^{1}$ Leibniz Institute of Atmospheric Physics at the University of Rostock (IAP), Kühlungsborn, Germany \\ ${ }^{2}$ German Aerospace Center (DLR), Institute of Atmospheric Physics (IPA), Wessling, Germany \\ ${ }^{a}$ now at: SRON Netherlands Institute for Space Research, Utrecht, the Netherlands \\ Correspondence to: Andreas Schneider (a.schneider@sron.nl)
}

Received: 7 October 2016 - Discussion started: 18 November 2016

Revised: 12 May 2017 - Accepted: 18 May 2017 - Published: 30 June 2017

\begin{abstract}
Measurements of turbulent energy dissipation rates obtained from wind fluctuations observed with the balloon-borne instrument LITOS (Leibniz-Institute Turbulence Observations in the Stratosphere) are combined with simulations with the Weather Research and Forecasting (WRF) model to study the breakdown of waves into turbulence. One flight from Kiruna $\left(68^{\circ} \mathrm{N}, 21^{\circ} \mathrm{E}\right)$ and two flights from Kühlungsborn $\left(54^{\circ} \mathrm{N}, 12^{\circ} \mathrm{E}\right)$ are analysed. Dissipation rates are of the order of $0.1 \mathrm{~mW} \mathrm{~kg}^{-1}\left(\sim 0.01 \mathrm{~K} \mathrm{~d}^{-1}\right)$ in the troposphere and in the stratosphere below $15 \mathrm{~km}$, increasing in distinct layers by about 2 orders of magnitude. For one flight covering the stratosphere up to $\sim 28 \mathrm{~km}$, the measurement shows nearly no turbulence at all above $15 \mathrm{~km}$. Another flight features a patch with highly increased dissipation directly below the tropopause, collocated with strong wind shear and wave filtering conditions. In general, small or even negative Richardson numbers are affirmed to be a sufficient condition for increased dissipation. Conversely, significant turbulence has also been observed in the lower stratosphere under stable conditions. Observed energy dissipation rates are related to wave patterns visible in the modelled vertical winds. In particular, the drop in turbulent fraction at $15 \mathrm{~km}$ mentioned above coincides with a drop in amplitude in the wave patterns visible in the WRF. This indicates wave saturation being visible in the LITOS turbulence data.
\end{abstract}

\section{Introduction}

Gravity waves transport energy and momentum and are thus an important factor in the atmospheric energetics. Typically, they are excited in the troposphere and propagate upwards and horizontally. Due to decreasing density, the amplitudes increase with altitude in the absence of damping. Eventually, the waves become unstable and break, producing turbulence and dissipation, and thereby depose their energy and momentum. This mechanism has been suggested by Hodges (1967) to explain turbulence in the mesosphere. There are two variants of wave breaking (e.g. Hocking, 2011, Sect. 9): first catastrophic wave breaking, in which the wave is completely annihilated (e.g. Andreassen et al., 1994), and second wave saturation, in which a wave loses energy to turbulence so that the amplitude does not increase further, meaning that the wave breaks only partially (e.g. Lindzen, 1981). Hines (1991) defines saturation to imply that the wave amplitude is at a maximum and the excess energy is shed by physical processes to prevent further growth. There are several theories for saturation (Fritts and Alexander, 2003, Sect. 6.3), and the phenomenon has been observed as well. For example, using a balloon-borne instrument, Cot and Barat (1986) measured a gravity wave in winds and temperature with vertical wavelength of $\sim 1 \mathrm{~km}$ and nearly constant amplitude over $\sim 5 \mathrm{~km}$ height. Simultaneously they observed several turbulent patches collocated with negative temperature gradient and Richardson numbers between 0.3 and 6 . They concluded that clear air turbulence is related to a long-period wave via shear instability. The dissipated energy approximately corresponded to the energy loss necessary to keep the wave amplitude constant. Franke and Collins (2003) ob- 
served gravity waves in the mesosphere with $\mathrm{Na}$ lidar and found upwards-propagating waves still present (with less amplitude) above an overturning region. Catastrophic wave breaking has been observed, for example, in the lowermost stratosphere by Worthington (1998) and Pavelin et al. (2001) with radar and radiosonde. Model studies of breaking gravity waves have, for example, been carried out by Achatz (2005) and by Fritts and Wang (2013), Fritts et al. (2016), who performed direct numerical simulations (DNS) of a gravity wave superposed by fine-scale shear.

Regarding turbulence measurements, there are two aspects of importance: first, the energy dissipation, and secondly the diffusive properties. We will concentrate on the former. Large-scale diffusion in the stratosphere is a complex process due to the intermittent nature of the turbulence there, as summarised in some detail by Osman et al. (2016), among others. A relatively extensive data set exists for the troposphere and tropopause region (e.g. Lilly et al., 1974; Hauf, 1993; Cho et al., 2003), but in the middle stratosphere observations are sparse. Remote sensing is mainly performed by radars in the troposphere and lower stratosphere as well as in the mesosphere (see Wilson, 2004, for an overview), and with satellites in the upper stratosphere (e.g. Gavrilov, 2013). In situ observations in the middle stratosphere have been carried out with balloon-borne instruments. Pioneering work has been done by Barat (1982) and Dalaudier et al. (1994). An instrument with a similar anemometer has been developed by Yamanaka et al. (1985). Indirect measurements using the Thorpe method were taken by Luce et al. (2002), Clayson and Kantha (2008) and others, mainly using standard radiosondes. A recent high-resolution balloon-borne instrument for the direct measurement of turbulent wind fluctuations is Leibniz Institute Turbulence Observations in the Stratosphere (LITOS) (Theuerkauf et al., 2011), which can resolve the inner scale of turbulence in the stratosphere for the first time. This state of the art instrument is used for this study.

To study waves breaking into turbulence, a wide range of scales from kilometres (the wavelength of GWs) to millimetres (the viscous subrange of turbulence) have to be resolved. This cannot be performed by a single instrument. Thus several techniques have to be combined. In this study, LITOS is used for the turbulence part and radiosonde observations from the same gondola are used for local atmospheric background conditions. To put the observations into a geophysical context and to obtain information about waves, regional model simulations with the WRF (Weather Research and Forecasting model) driven by reanalysis data are applied. Three flights are analysed, comprising one from Kiruna (northern Sweden, 67.9 $\mathrm{N}, 21.1^{\circ} \mathrm{E}$ ) and two from Kühlungsborn (northern Germany, 54.1 ${ }^{\circ} \mathrm{N}, 11.8^{\circ} \mathrm{E}$ ).

This paper is structured as follows: Sect. 2 gives an overview of the instrument LITOS and the data retrieval (Sect. 2.1) as well as the WRF model set-up (Sect. 2.2). The results for three different flights are presented in Sect. 3.
These are interrelated and discussed in Sect. 4, and finally conclusions are drawn in Sect. 5.

\section{Instrumentation and model}

\subsection{Balloon-borne measurements}

LITOS (Leibniz-Institute Turbulence Observations in the Stratosphere) is a balloon-borne instrument used to observe small-scale fluctuations in the stratospheric wind field (Theuerkauf et al., 2011). The wind measurements are taken with a constant temperature anemometer (CTA) which has a precision of a few $\mathrm{cm} \mathrm{s}^{-1}$. It is sampled with $8 \mathrm{kHz}$ yielding a sub-millimetre vertical resolution at $5 \mathrm{~m} \mathrm{~s}^{-1}$ ascent rate. Thus the inner scale of turbulence is typically covered. A standard meteorological radiosonde (Vaisala RS92 or RS41) is used to record atmospheric background parameters. LITOS was launched three times as part of a $\sim 120 \mathrm{~kg}$ payload from Kiruna $\left(67.9^{\circ} \mathrm{N}, 21.1^{\circ} \mathrm{E}\right)$ within Balloon Experiments for University Students (BEXUS) 6, 8, and 12 in 2008, 2009, and 2011, respectively (Theuerkauf et al., 2011; Haack et al., 2014; Schneider et al., 2015). The second generation of the small version of the instrument is an improvement on the one described by Theuerkauf et al. (2011) and consists of a spherical payload of $\sim 3 \mathrm{~kg}$ weight. It is suspended $\sim 180 \mathrm{~m}$ below a meteorological rubber balloon. Two CTA sensors are mounted on booms protruding at the top of the gondola. The instrument was launched several times from the IAP's site at Kühlungsborn $\left(54.1^{\circ} \mathrm{N}, 11.8^{\circ} \mathrm{E}\right)$, e.g. on 27 March 2014, 6 June 2014, and 12 July 2015.

In this paper, flights are only taken into account when data from more than one CTA sensor on the same gondola are available. Summarised, the data analysis is performed in three steps. First, the dissipation rate is retrieved similarly to the procedure described by Theuerkauf et al. (2011). Then the $\varepsilon$ values from both sensors are compared to detect sections where one sensor is possibly affected by the wake of ropes. Finally, the remaining spectra are manually inspected to sort out cases for which both sensors potentially have been affected. Another source of artificial turbulence is the wake of the balloon (Barat et al., 1984). Typically, the wake influences both sensors similarly and cannot be detected by the above methods. Therefore, we limit our analysis to flights and altitude regions, where wake effects do not play a role due to sufficient wind shear that brings the payload out of the balloon's wake.

The details of the retrieval are as follows: the data of the ascent are split into windows with depths of $5 \mathrm{~m}$ altitude with $50 \%$ overlap. In each window, the mean value is subtracted, and the periodogram is computed, which is an estimation of the power spectral density (PSD). The periodogram is smoothed with a Gaussian-weighted running average. The instrumental noise level is detected and subtracted. Initially, turbulence is assumed to occur in each window and 
thus the algorithm attempts to fit the Heisenberg (1948) model for fully developed turbulence in the form given by Lübken and Hillert (1992) and Theuerkauf et al. (2011) to the observed spectrum (see Eq. A3 in Appendix A). If the fit succeeds, the inner scale $l_{0}$ is obtained. This leads to the energy dissipation rate $\varepsilon$ given by

$\varepsilon=c_{l_{0}}^{4} \frac{v^{3}}{l_{0}^{4}}$,

where $v$ is the kinematic viscosity (known from the radiosonde measurement) and $c_{l_{0}}$ is a constant depending on the type of sensor. The determination of $c_{l_{0}}$ for our sensor configurations is described in Appendix A. Non-turbulent (or disturbed) spectra manifest in bad fits which are sorted out with the following set of criteria:

- The noise level detection fails, which usually means that the noise is not white; i.e. the periodogram is disturbed at small scales.

- The mean logarithmic difference between data and fit exceeds a given threshold. This condition captures cases where the fit does not describe the data well, e.g. when no turbulence is present so that the periodogram does not follow the form of the turbulence model.

- The inner scale $l_{0}$ lies outside the fit range. This means that the bend in the spectrum is not within the fit range and thus the fit is not meaningful, allowing no useful retrieval of $\varepsilon$. That can occur when the spectrum does not have the expected form of the turbulence model, when the inner scale lies at very small scales where the periodogram is dominated by noise, or when the periodogram is disturbed.

- The fit width is smaller than a threshold; in this case the fit is determined by too few data points.

- The value of the periodogram at $l_{0}$ is too close to the value of the noise level, which means too small a part of the viscous subrange is resolved.

- The slope of the fit function at the small-scale end is less than a given threshold (less steep than $m^{-4}$, where $m$ is the vertical wave number). This indicates that the bend in the spectrum is not well covered by the fit and the data.

If one of the above conditions applies, the spectrum does not follow the form for fully developed turbulence; thus $\varepsilon$ is set to zero. Requiring the spectrum to follow Heisenberg's turbulence model may exclude turbulence that is not fully developed. However, it is not feasible to retrieve $\varepsilon$ in cases where the periodogram does not follow the turbulence model.

Sometimes a sensor has been located in the wake of a rope supporting the gondola and the other sensor has not, causing the $\varepsilon$ values of both sensors to differ by up to 5 orders of magnitude. To sort out such sections, altitude bins for which the dissipation rate from both sensors deviates by more than a factor of 15 are discarded. For the flights with a small payload, the remaining spectra have been inspected manually for sections where both sensors have been affected by the rope wake, and those that look suspicious have been taken out. A spectrum is regarded as wake-affected if it has a plateau in PSD near $10 \mathrm{~cm}$ spatial scale, which is estimated to be the extent of a Kármán vortex street originating from the lines supporting the gondola. This problem of wake effects from the ropes does not occur for the BEXUS flights, where the sensors were placed further away from the supporting lines. For all other altitude bins the average of both sensors is taken.

On the other hand, for the BEXUS flight the distance between the balloon and the payload was only $50 \mathrm{~m}$, i.e. comparatively small. Thus, the payload flew through the wake of the balloon for a considerable duration of the flight. Therefore, only limited altitude sections with large wind shears are considered for this flight.

To quantify the stability of the atmosphere, the gradient Richardson number $R i=N^{2} / S^{2}$ is used, which is the ratio of the squared Brunt-Väisälä frequency $N^{2}$ and the square of the vertical shear of the horizontal wind $S^{2}$. The BruntVäisälä frequency can be written as $N^{2}=\frac{g}{\Theta} \frac{\mathrm{d} \Theta}{\mathrm{d} z}$, where $\Theta$ is the potential temperature and $g$ is the acceleration due to gravity. The wind shear is defined as $S^{2}=\left(\frac{\mathrm{d} u}{\mathrm{~d} z}\right)^{2}+\left(\frac{\mathrm{d} v}{\mathrm{~d} z}\right)^{2}$, where $u$ and $v$ are the zonal and meridional wind components, respectively. The Richardson number represents the ratio of buoyancy forces (which suppress turbulence) to shear forces (which generate turbulence). According to a theory for plane-parallel flow established by Miles (1961) and Howard (1961), turbulence occurs below a critical Richardson number of $R i_{\mathrm{c}}=1 / 4$. The general applicability of that criterion was recently questioned based on measurements (e.g. Balsley et al., 2008) and model simulations (e.g. Achatz, 2005). Often the shear is not strictly horizontal so that the theory by Miles (1961) and Howard (1961) is not applicable, as pointed out by Achatz (2005). To take into account slanted shear, Hines (1988) proposed a concept of slantwise instability. However, the Richardson number is still useful as an estimation of stability. The Richardson number also depends on the scale on which it is computed (Balsley et al., 2008; Haack et al., 2014). Usually, computing $R i$ on a smaller scale yields locally smaller numbers, since for a computation on larger scales an average over regions with small and large $R i$ is obtained. In this study $R i$ is retrieved from the radiosonde measurements. In order not to dominate the derivatives by instrumental noise, the potential temperatures and winds are smoothed with a Hann-weighted running average over $150 \mathrm{~m}$ prior to differentiation with central finite differences. 


\subsection{Model simulations}

Mesoscale numerical simulations are performed with the Weather Research and Forecasting (WRF) model, version 3.7 (Skamarock et al., 2008). Two nested domains with horizontal resolutions of 6 and $2 \mathrm{~km}$ and time steps of 15 and $5 \mathrm{~s}$, respectively, are applied. In the vertical direction 138 terrain following levels with stretched level distances of $80 \mathrm{~m}$ near the surface and $300 \mathrm{~m}$ in the stratosphere are used and the model top is set to $2 \mathrm{hPa}$ (about $40 \mathrm{~km}$ altitude) for the BEXUS flights and $5 \mathrm{hPa}$ (about $32 \mathrm{~km}$ altitude) for the flights from Kühlungsborn. At the model top a $7 \mathrm{~km}$ thick Rayleigh damping layer is applied to prevent wave reflections (Klemp et al., 2008); i.e. the top of the damping layer is the model top. Physical parameterisations contain the rapid radiative transfer model longwave scheme (Mlawer et al., 1997), the Goddard shortwave scheme (Chou and Suarez, 1994), the Mellor-Yamada-Nakanishi-Niino boundary layer scheme (Nakanishi and Niino, 2009), the Noah land surface model (Chen and Dudhia, 2001), the WRF singlemoment 6-class microphysics scheme (WSM6; Hong and Lim, 2006) and the Kain-Fritsch cumulus parameterisation scheme (Kain and Fritsch, 1990). The initial and boundary conditions are supplied by ECMWF (European Centre for Medium-Range Weather Forecasts) operational analyses on 137 model levels with a temporal resolution of $6 \mathrm{~h}$. In the WRF a temporal output interval of $1 \mathrm{~h}$ is used, data interpolated along the flight track are output with an interval of $5 \mathrm{~min}$. Simulations are initialised 5 to $6 \mathrm{~h}$ before the launch time of the balloon. The computation of turbulent kinetic energy (TKE) is done by the boundary layer scheme and described in Nakanishi and Niino (2009). It is based on a prognostic equation which is solved additionally to the equations of motion and which includes transport, shear production, buoyancy production and dissipation terms. Shear and buoyancy terms include deformation and stability effects of the resolved flow and are related to turbulent motions by the horizontal and vertical eddy viscosities. The equation operates on the scale of the grid size.

In this paper WRF simulations are used to get an overview of the meteorological situation. Ehard et al. (2016) showed that regions of GW breaking can be simulated by WRF simulations with horizontal grid distances of $2 \mathrm{~km}$ and a similar model set-up by means of convective overturning and reduced Richardson numbers. Here, the TKE output from the model is also used to identify regions of intensified turbulent mixing in the atmosphere along the balloon flight tracks. This can be a hint that observed turbulence was caused by large-scale GW breaking. It is not intended to quantitatively compare observed dissipation rates with simulated regions of enhanced TKE values.

\section{Results}

\subsection{The BEXUS 12 flight (27 September 2011)}

The BEXUS 12 flight was launched from Kiruna on 27 September 2011 at 17:36 UT.

Figure 1a and $\mathrm{b}$ show atmospheric conditions observed by the radiosonde on board the payload. Temperatures decreased up to the tropopause at $10.3 \mathrm{~km}$, excepting some small inversion layers. Above, there was a sharp increase in temperature known as tropopause inversion layer (TIL) (Birner et al., 2002; Birner, 2006). Higher up, temperatures slightly decreased. Winds came from the north-west near the surface and reversed between $\sim 6$ and $10 \mathrm{~km}$. The reversal caused nearly the opposite wind direction at $9 \mathrm{~km}$ altitude compared to $5 \mathrm{~km}$, and a change of sign in both wind components. It further entailed strong wind shear below the tropopause, causing low Richardson numbers (below the critical number of 1/4). Above the tropopause the wind field showed signatures of gravity wave activity with short wavelengths and no obvious altitude-dependent structure. In the stratosphere, Richardson numbers were generally larger than in the troposphere.

Figure 1d depicts observed dissipation rates. Each blue cross corresponds to an altitude bin classified as turbulent (as described in Sect. 2.1). The orange curve depicts a Hannweighted running average over $500 \mathrm{~m}$. Please note that large sections in the troposphere and stratosphere are subject to wake influence (marked grey) due to the small distance of only $50 \mathrm{~m}$ between the payload and the balloon. These sections are generally not discussed here. Between 9 and $10 \mathrm{~km}$ there was a thick layer with high dissipation. As described above, this altitude region featured low Richardson numbers caused by high wind shears. Thus turbulence was presumably induced by dynamic instability. Additionally, at this altitude a wind reversal was observed which caused filtering of gravity waves with phase velocities equal to the background winds (if present). Most probably, these high dissipation rates are not caused by wake because calculations show that the gondola was outside the wake in this altitude section due to the large wind shear. Furthermore, the dissipation rates are even larger than typical wake turbulence.

WRF model simulations were performed for the time and place of the flight. To show that these produced reasonable results, model winds and temperatures interpolated along the flight trajectory are plotted in Fig. 1a along with the radiosonde profiles. Observed and modelled results compare very well; the only difference is that the radiosonde data contain signatures from small-scale gravity waves which WRF cannot resolve. In Fig. 2, model snapshots at the middle of the ascent are shown. Panel (a) depicts horizontal winds at $850 \mathrm{hPa}$. Westerly winds flowed over the Scandinavian mountains, which are expected to have excited mountain waves. Another potential source of gravity waves is geostrophic adjustment. Bending stream lines are visible, e.g. 

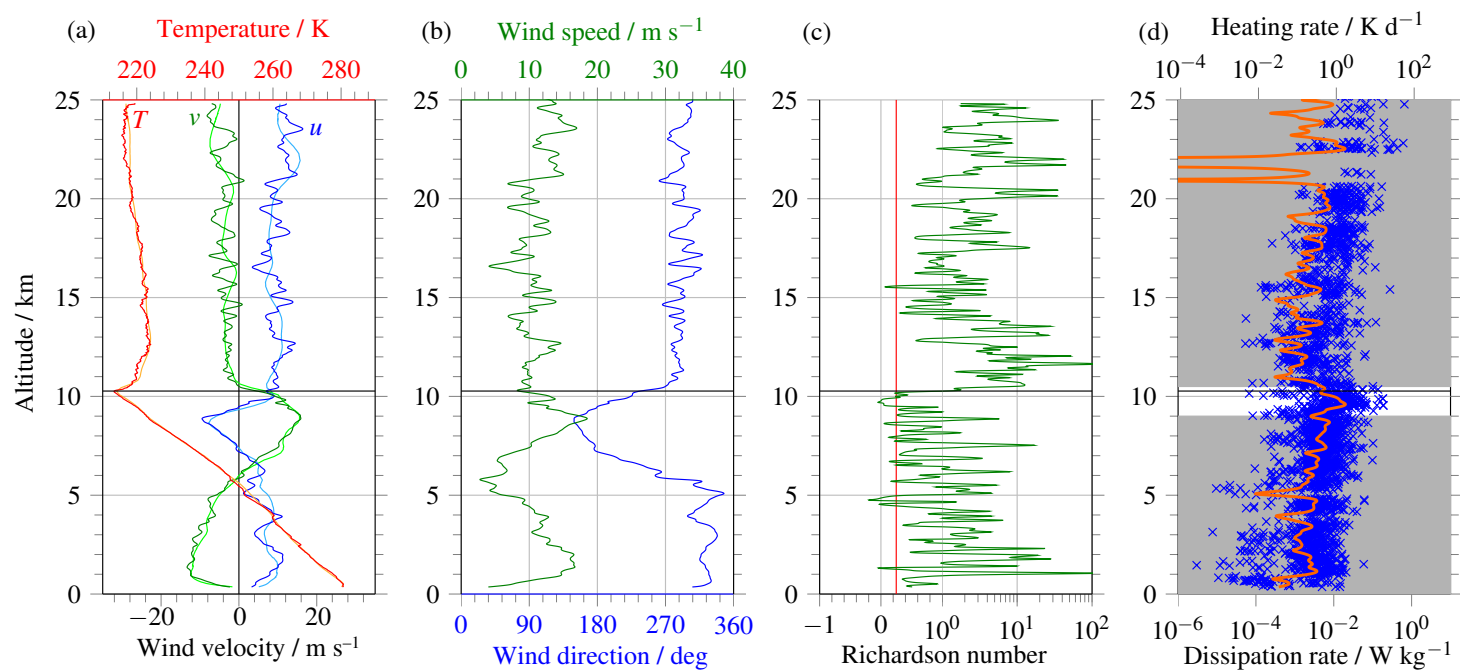

Figure 1. Observations during the BEXUS 12 flight. (a) Zonal winds $u$ (blue), meridional winds $v$ (green), and temperatures $T$ (red) from the radiosonde. The light blue, light green, and orange curves show the corresponding results from the WRF model interpolated along the balloon trajectory. (b) Wind direction (blue) and horizontal wind speed (green) from the radiosonde. (c) Richardson number Ri computed from the radiosonde data, using a smoothing over $150 \mathrm{~m}$ prior to numerical differentiation. The $R i$ axis is split at 1 into a linear and a logarithmic part. The red line shows the critical Richardson number, 1/4. (d) Energy dissipation rates $\varepsilon$ observed by LITOS. The blue crosses mark single turbulent spectra computed on a $5 \mathrm{~m}$ grid with $50 \%$ overlap, the orange curve shows a Hann-weighted running average over $500 \mathrm{~m}$ (non-turbulent bins count as zero in the average). The top axis gives the heating rate due to turbulent dissipation, $\mathrm{d} T / \mathrm{d} t=\varepsilon / c_{\mathrm{p}}$. The grey areas mark the regions with likely wake influence. The horizontal black line in all four panels marks the tropopause.

over the Scandinavian mountains, west of the flight track. Panel (b) presents a vertical section of horizontal winds and potential temperatures. It demonstrates that the jet $(\sim 7$ to $10 \mathrm{~km}$ altitude) had a local structure and involved strong wind shears.

With a grid resolution of $2 \mathrm{~km}$ WRF can resolve waves with horizontal wavelengths larger than about $10 \mathrm{~km}$. These waves can be seen, for example, in the vertical winds, which are used as a proxy. This quantity is plotted in Fig. 2c. Strong wave-like patterns are visible especially over the Scandinavian mountains, which correspond to the mountain wave excitation mentioned above. Weaker wave patterns are visible near the flight trajectory, downstream of the mountains. Between roughly $x=400 \mathrm{~km}$ and $x=550 \mathrm{~km}$, the wave patterns change at tropopause height (approximately $10 \mathrm{~km}$ altitude): above, there is less amplitude than below. This is ascribed to the wave breaking and filtering mentioned before. Filtering means catastrophic breaking of waves; i.e. a wave that is filtered is annihilated. Further upwards the amplitude increases slowly.

Waves can propagate over considerable distances and times. Therefore it is not sufficient to look at potential sources in the vicinity of the flight track. Even if sources are found, the waves may have propagated to other places (away from the point of interest), while waves from sources outside the domain may have propagated to the location of observation. For resolved waves the model takes care of these issues. Waves seen in the WRF at the location of the flight may have travelled from remote places, yet the important information is not their origin, but that they were present during the measurement.

To trigger turbulence, wave breaking is necessary. Such events are triggered by dynamic or convective instabilities or by wave-wave interactions (e.g. Fritts and Alexander, 2003). In the WRF, the breakdown to turbulence is parameterised by solving a prognostic equation for TKE, which is based on production terms due to shear and buoyancy obtained from the resolved flow. TKE is plotted in Fig. 2d. It peaks near $10 \mathrm{~km}$ height at the location of the flight. This corresponds nicely to the intense turbulent layer observed by LITOS. It is reproduced in the WRF due to the shear instability on scales resolved by the model, highlighting the geophysical significance of the layer.

\subsection{The 27 March 2014 flight}

A small LITOS payload of second generation was launched from Kühlungsborn on 27 March 2014 at 10:10 UT. It was carried by a comparatively small $(3000 \mathrm{~g})$ balloon and a $60 \mathrm{~m}$ dereeler.

Figure 3a shows temperatures smoothed over 15 data points $(\sim 150 \mathrm{~m})$ as well as zonal and meridional winds. The smoothing is necessary because for this flight the temperature measurement is perturbed by radiation effects as the radiosonde was incorporated in the main payload; these effects get worse with increasing altitude. Temperatures decreased up to the tropopause at $9 \mathrm{~km}$. Between 9 and $\sim 30 \mathrm{~km}$ altitude 

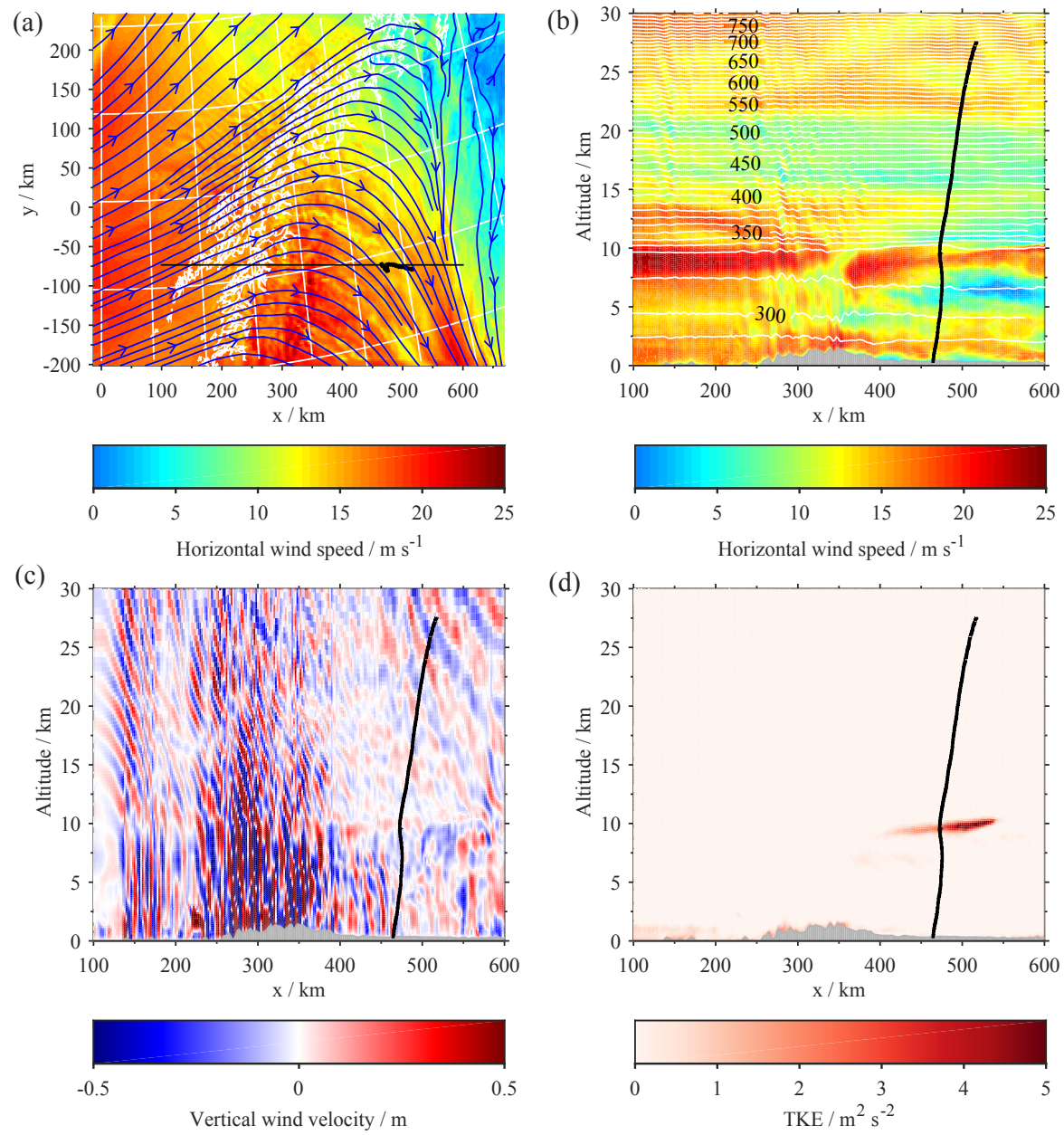

Figure 2. (a) Map of horizontal winds at $850 \mathrm{hPa}$, (b) vertical section of horizontal winds, (c) vertical section of vertical winds, and (d) vertical section of turbulent kinetic energy (TKE) from WRF simulations for 27 September 2011, 18:00 UT. The black curves visualise the trajectory of the BEXUS 12 flight. In (a), the blue streamlines show the wind direction, the white lines visualise coastlines and a latitude/longitude grid, and the black line indicates the location of the vertical sections. In (b), the white isolines show potential temperature with labels in Kelvin.

they stayed nearly constant and started to increase further upwards. Winds were easterly and turned northerly above $\sim 20 \mathrm{~km}$ altitude. A strong southeasterly jet was present between $\sim 6$ and $10 \mathrm{~km}$ height. Superposed are signatures of small-scale gravity waves. Wind shears originating from the jet may have excited turbulence and/or waves. The effect of the shear is visible as a layer with enhanced dissipation at this altitude (see below). Richardson numbers are shown for altitudes below $9.4 \mathrm{~km}$ only because they involve derivatives of the temperature profile, which was disturbed by radiation effects as described above.

Dissipation rates are presented in Fig. 3d. The data below $650 \mathrm{~m}$ altitude are affected by the unwinding of the dereelers while the data above the tropopause are subject to wake influence. Therefore, these are discarded and not shown in the plot. Dissipation rates varied over several orders of magnitude within small altitude ranges (typically a few $10 \mathrm{~m}$ ). The running average shows some structure in the troposphere, e.g. a few layers that are standing out with larger rates. Most prominently this can be seen near $8 \mathrm{~km}$. That is in the same altitude as the wind shear due to the jet, which speaks for shear-induced turbulence. Precisely, there were two turbulent layers from 7.5 to $7.9 \mathrm{~km}$ and from 8.1 to $8.3 \mathrm{~km}$ height; within both, Richardson numbers were below 1 and partly below $1 / 4$. Other sheets with large dissipation were detected, e.g. near $6.1 \mathrm{~km}$ and around $3.0 \mathrm{~km}$ altitude.

To validate the corresponding WRF simulations, winds and temperatures interpolated to the flight track are plotted in Fig. 3a. They agree very well with the radiosonde data.

Figure 4 depicts WRF results for the time of the flight. Panel (a) shows horizontal winds at $850 \mathrm{hPa}$, which were easterly or south-easterly. In panel (b) horizontal winds are depicted as altitude section, showing that the strong jet did not have much structure in a horizontal direction, while the sharp vertical structure is reproduced as observed by the radiosonde. Panel (c) shows a vertical profile of vertical winds. 

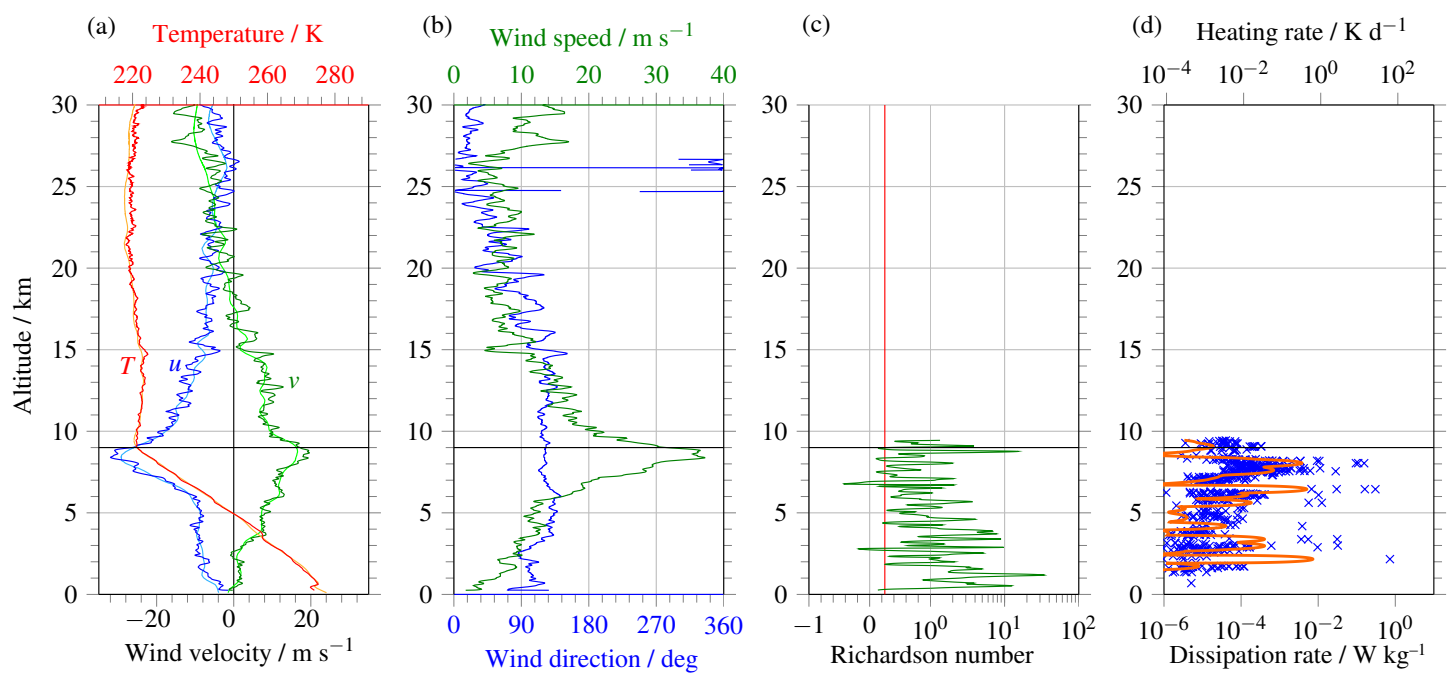

Figure 3. Same as Fig. 1, but for the flight from Kühlungsborn at 27 March 2014. Due to disturbances of the temperature data, temperatures are smoothed in the plot in (a), and Richardson numbers are shown only for altitudes lower than $9.4 \mathrm{~km}$. The dissipation profile excludes the lowermost $650 \mathrm{~m}$ due to disturbances from the launch procedure (dereeling of the payload suspension), and the part above $9.4 \mathrm{~km}$ altitude due to potential wake effects from the balloon.

Wave patterns are visible, which stretch over the whole altitude range. Particularly, a superposition of a wave with long vertical wavelength $\left(\lambda_{z} \approx 8 \mathrm{~km}\right)$ and nearly horizontal phase fronts and waves with short horizontal wavelength (10 to $20 \mathrm{~km}$ ) and phase fronts in the vertical can be seen. Figure $4 \mathrm{~d}$ shows the TKE. Outside the boundary layer there is an enhancement near $7.5 \mathrm{~km}$ altitude. It corresponds nicely to a thick, strong turbulent layer in the measurement by LITOS between $\sim 7$ and $8.5 \mathrm{~km}$ height. Within this observed turbulent layer, which in fact consists of several layers, Richardson numbers are smaller than 1 almost everywhere and at times smaller than $1 / 4$.

\subsection{The 11/12 July 2015 flight}

A night-time flight with LITOS was launched from Kühlungsborn on $11 / 12$ July 2015 , at midnight local time (22:01 UT on 11 July). A dereeler of $180 \mathrm{~m}$ (with a $3000 \mathrm{~g}$ balloon) was used for payload suspension, making balloon wake effects negligible for this flight. The radiosonde was positioned $60 \mathrm{~m}$ below the main payload to avoid disturbances of the temperature sounding.

The observed background parameters are depicted in Fig. 5a and b. Westerly winds prevailed up to $\sim 19 \mathrm{~km}$ altitude, whereas above winds came from the east. This change in direction was not associated with a significant wind shear because velocities were small in that altitude region. A jet is visible at about $10 \mathrm{~km}$ height. Superposed on the winds are signatures of small-scale gravity waves. Above the tropopause at $11.3 \mathrm{~km}$ altitude there was a small tropopause inversion layer. Higher up temperatures remained rather constant up to $\sim 20 \mathrm{~km}$, where they started to increase.
Richardson numbers were typically lower than for the other flights, indicating less stability. There are several layers where the Richardson number is below the critical limit of $R i_{\mathrm{c}}(1 / 4)$. These layers are relatively thin.

Energy dissipation rates (data below $550 \mathrm{~m}$ are excluded due to disturbances from the launch procedure) showed a strong patchy structure, with enhanced dissipation at, for example, $\sim 2.0,3.8,7.2,8.9,11.0,12.1$, and $14.3 \mathrm{~km}$. These layers of intense turbulence mostly corresponded to Richardson numbers smaller than $R i_{\mathrm{c}}=1 / 4$, or at least to $R i<1$. But particularly in the lower stratosphere between 11 and $15 \mathrm{~km}$, turbulence also occurred for high Richardson numbers. It should be kept in mind that the Richardson number depends on the scale on which it is computed (e.g. Balsley et al., 2008; Haack et al., 2014). A higher resolution (i.e. computing $R i$ on smaller scales) may result in locally smaller $R i$ numbers, because the computation on large scales yields a kind of average. Similarly, in large eddy simulations Paoli et al. (2014) found larger Richardson numbers for smaller model resolutions (i.e. larger scales). Here, due to measurement noise a smoothing over $150 \mathrm{~m}$ has been applied before computing $R i$, determining the resolution. However, this issue cannot explain the whole discrepancy. In simulations of gravity waves, Achatz (2005) found instabilities and onset of turbulence for Richardson numbers both smaller and larger than $1 / 4$. He noted that the theory by Miles (1961) and Howard (1961) is not applicable to his simulations because the gravity wave phase propagation and thus the waveinduced shear is slanted. In the real atmosphere, waves usually propagate at a tilt (i.e. the shear is not orthogonal to the altitude axis). Hines (1988) has already discussed slantwise static instabilities created by gravity waves. He developed 

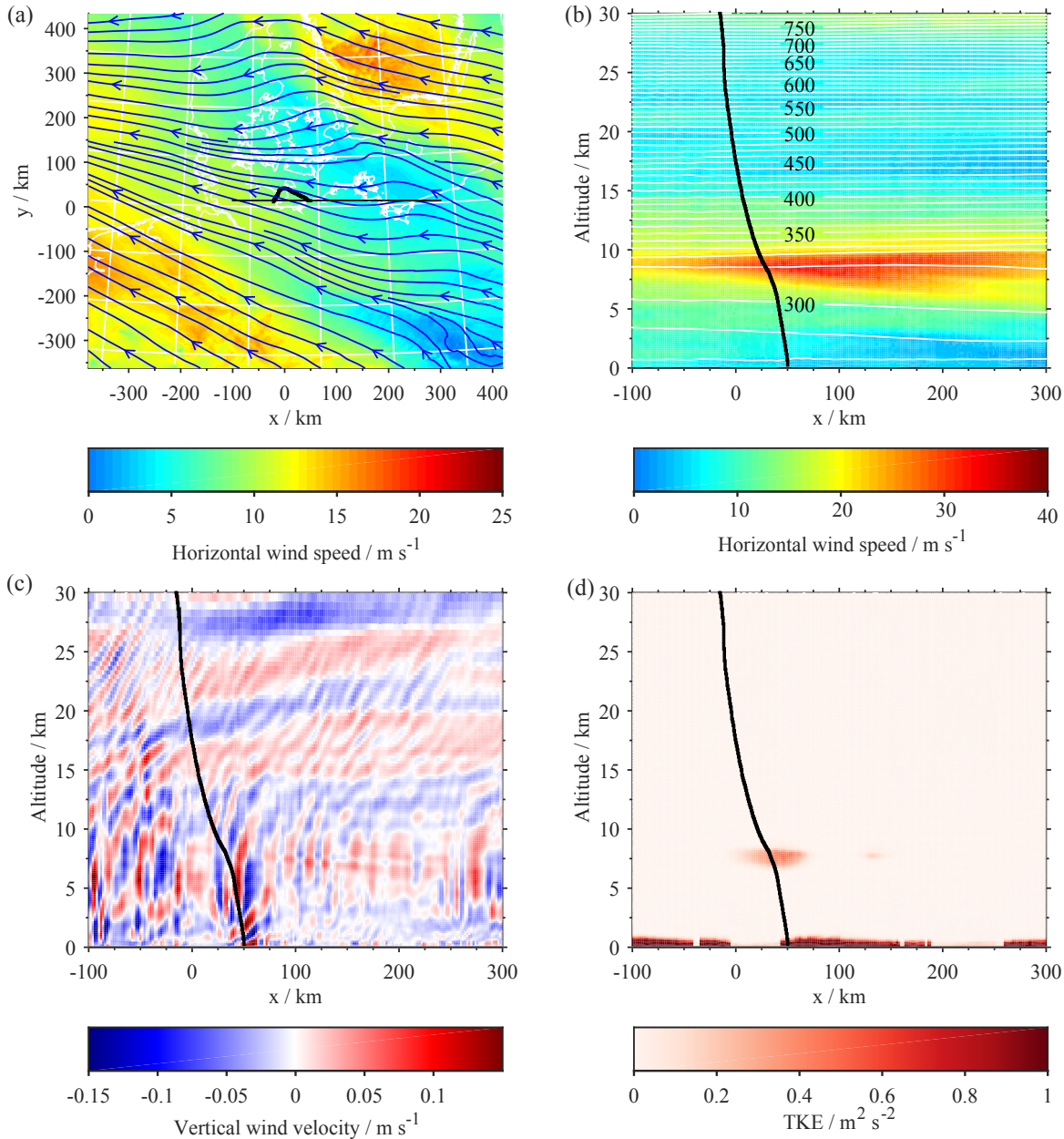

Figure 4. Same as Fig. 2, but for WRF simulations for 27 March 2014, 11:00 UT.

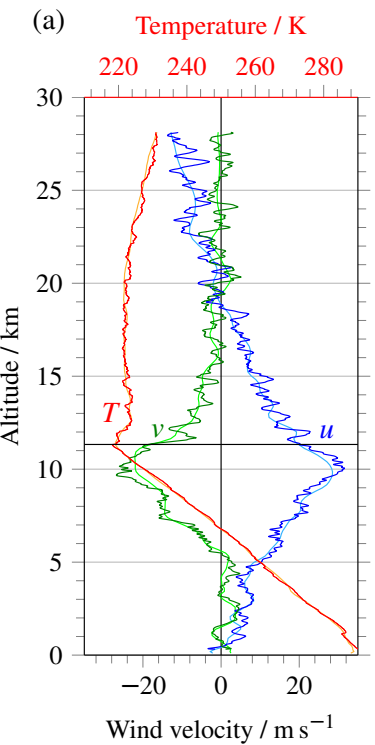

(b) Wind speed $/ \mathrm{m} \mathrm{s}^{-1}$

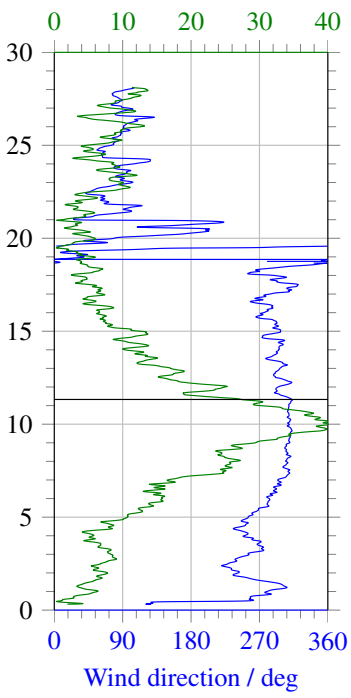

(c)

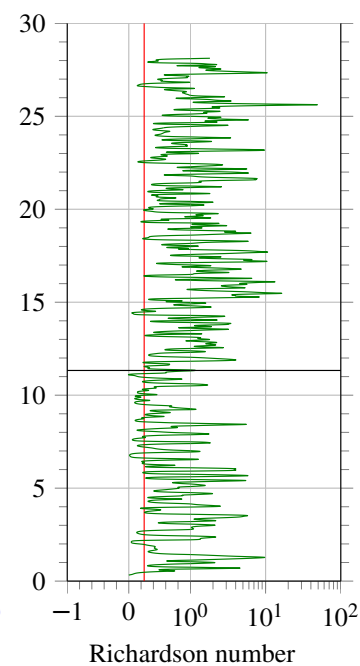

(d) Heating rate $/ \mathrm{Kd}^{-1}$

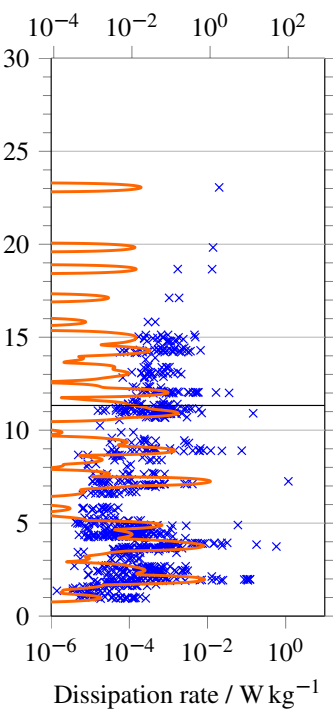

Figure 5. Same as Fig. 1, but for the flight from Kühlungsborn at 11/12 July 2015. The dissipation profile excludes the lowermost $550 \mathrm{~m}$ due to disturbances from the launch procedure (dereeling of the payload suspension). 


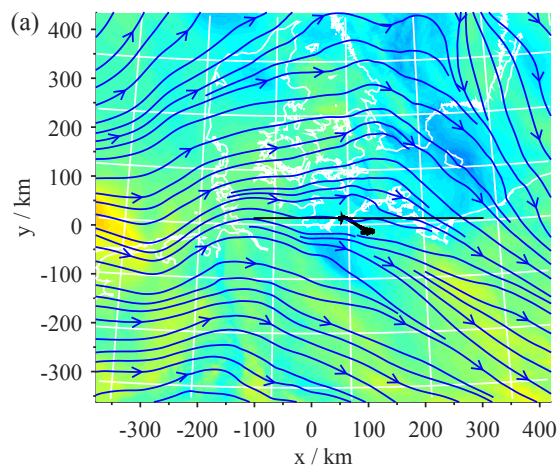

(b)
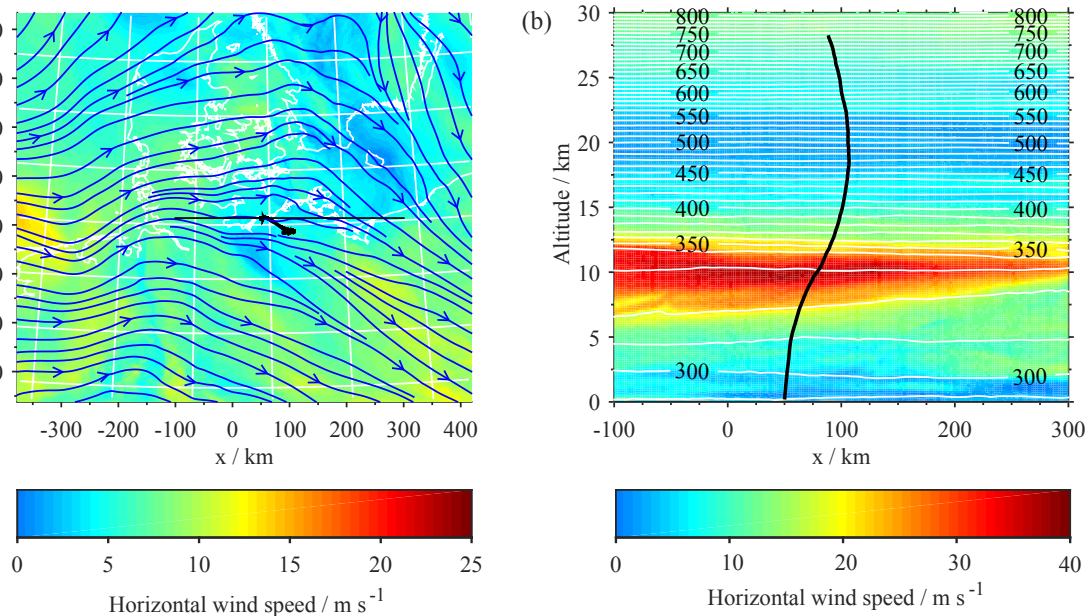

(c)

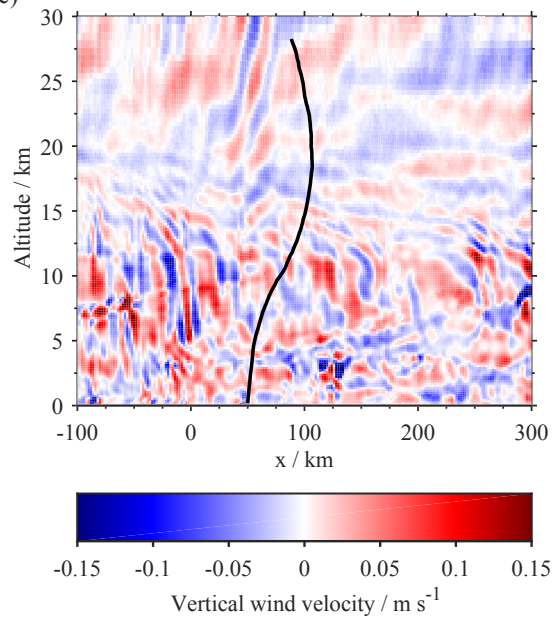

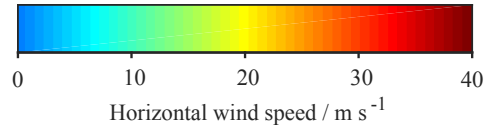

(d)

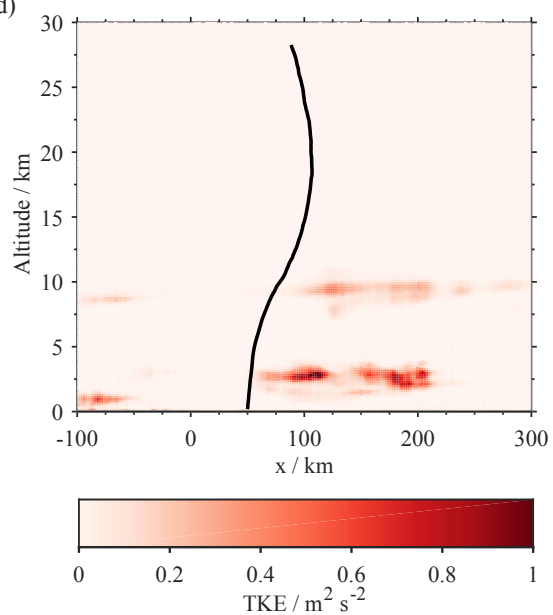

Figure 6. Same as Fig. 2, but for WRF simulations for 11 July 2015, 23:00 UT.

a wave period criterion for turbulence by comparing the efolding time of the (slantwise) instability with the period of the wave. Turbulence is more likely to occur for slantwise static instability than for vertical static instability. In the light of these comments, the violation of the Richardson criterion for the LITOS measurements is comprehensible.

Above $\sim 15 \mathrm{~km}$ altitude, hardly any turbulence was detected; only a few thin turbulent layers were observed. Thus above $15 \mathrm{~km}$ the average dissipation rate (for which no turbulence is counted as zero) was only $0.01 \mathrm{~mW} \mathrm{~kg}^{-1}$, while below $15 \mathrm{~km}$ it was $0.64 \mathrm{~mW} \mathrm{~kg}^{-1}$.

Results from corresponding WRF simulations are depicted in Fig. 6. Horizontal winds at the $850 \mathrm{hPa}$ level were mainly westerly. The altitude section shows that the strong jet did not have much variation in the horizontal direction. Vertical winds reveal wave patterns that are particularly intense around the tropopause and gradually become weaker near $\sim 15 \mathrm{~km}$, with less amplitude above. This drop in wave amplitude is at the same altitude as the drop in observed dissipation. The TKE has enlarged values around $3 \mathrm{~km}$ altitude and near the tropopause; however the enhancement is small at the flight path. Correspondingly, the thickness of the strong turbulent layers detected by LITOS is relatively small, meaning that these dissipative layers are potentially not resolved in the model.

\section{Discussion}

A comparison of the observed dissipation profiles and the wave patterns in the model vertical winds for the different flights suggests that more turbulence observed by LITOS comes along with stronger wave patterns visible in WRF, and vice versa. Particularly, this can be seen at 11/12 July 2015 at the drop in dissipation and wave amplitude at $\sim 15 \mathrm{~km}$ altitude. A similar feature has been observed during another flight at 6 June 2014 (not shown). Likewise, LITOS data exhibit a sharp drop in turbulence at $\sim 15 \mathrm{~km}$, and the corresponding WRF simulation shows strong wave patterns below $\sim 15 \mathrm{~km}$ and very weak ones above. For the troposphere, vertical winds in WRF show similar gravity wave amplitudes for all Kühlungsborn soundings, even if the wave structures are 
different. Accordingly, dissipation rates are generally similar, showing up as a highly structured profile that is partly related to shear instabilities measured by the radiosonde. This is also reflected in the WRF turbulent kinetic energy, attesting that the structures are sufficiently large to be resolved in WRF. The same is true for the turbulent layer below the tropopause observed during BEXUS 12.

The relation between waves and turbulence can also be seen in averages over altitude regions. For 12 July 2015 the most significant drop in mean dissipation does not happen at the tropopause where the stability increases due to the changing temperature gradient, but at $\sim 15 \mathrm{~km}$ where the wave activity decreases. Mean energy dissipation rates are $0.64 \mathrm{~mW} \mathrm{~kg}^{-1}$ below $15 \mathrm{~km}$ altitude and $0.01 \mathrm{~mW} \mathrm{~kg}^{-1}$ above. Consistent with these rates, the average absolute vertical flux calculated from WRF data as a measure for wave activity is $64 \mathrm{~mW} \mathrm{~m}^{-2}$ below $15 \mathrm{~km}^{2}$ and $6.9 \mathrm{~mW} \mathrm{~m}^{-2}$ above.

We interpret this behaviour as the effect of wave saturation. As described in the introduction, a saturated wave looses part of its energy to turbulence so that the amplitude does not grow further. Such effects have already been observed, for example, by Cot and Barat (1986), who measured a gravity wave with almost constant amplitude over an altitude range of $5 \mathrm{~km}$ and collocated isolated turbulent patches with a dissipation rate approximately accounting for the energy loss of the wave. Franke and Collins (2003) found regions of strong overturning, and upwards-propagating waves are present below as well as (with less amplitude) above the overturning region. They argue that, depending on the amplitude, a breaking wave is not always completely annihilated, but the amplitude may be modulated in a highly non-linear event. Nappo (2002, p. 125) states that "gravity wave and turbulence are often observed to exist simultaneously." Via the process of wave saturation, the occurrence of waves is connected to the intensity of turbulence. Pavelin et al. (2001) observed intense turbulence in the lowermost stratosphere during a period of maximal wave intensity using radar at Aberystwyth $\left(52.4^{\circ} \mathrm{N}, 4.0^{\circ} \mathrm{W}\right)$, which supports the above hypothesis.

Saturation theories proposed several mechanisms, e.g. linear instability dynamics due to large wave amplitudes, nonlinear damping, or non-linear wave-wave interactions (Fritts and Alexander, 2003, Sect. 6.3). The present study cannot answer that debate, yet the relatively large Richardson numbers hint that non-linear interactions may play a role.

Mean dissipation rates observed by LITOS are of the order of $10^{-4} \mathrm{~W} \mathrm{~kg}^{-1}$ (roughly $0.01 \mathrm{~K} \mathrm{~d}^{-1}$ ). This is 2 orders of magnitude below typical solar or chemical heating rates which are of the order of $1 \mathrm{Kd}^{-1}$ (Brasseur and Solomon, 1986, Fig. 4.19b). However, within thin layers rates of $10^{-2}$ to $10^{-1} \mathrm{~W} \mathrm{~kg}^{-1}\left(\sim 1\right.$ to $\left.10 \mathrm{Kd}^{-1}\right)$ are observed, which is larger than solar heating. The low mean energy dissipation rates are not explicitly contained even in high-resolution models, which cannot describe the large intermittency. Only large layers with highly increased dissipation, as encountered, for example, during BEXUS 12, are captured.

Observed dissipation rates are partly larger than those reported by other publications using different methods. Barat (1982) obtained values between $1.4 \times 10^{-5}$ and $3.9 \times$ $10^{-5} \mathrm{~W} \mathrm{~kg}^{-1}$ from balloon measurements. Wilson et al. (2014) found $\varepsilon$ values between $3 \times 10^{-5}$ and $6 \times 10^{-4} \mathrm{~W} \mathrm{~kg}^{-1}$ in the upper troposphere from radar measurements. These are lower rates than the averages in this work, but within the range of the variability. Lilly et al. (1974) observed stratospheric dissipation rates between $7 \times 10^{-4}$ and $2 \times$ $10^{-3} \mathrm{~W} \mathrm{~kg}^{-1}$, depending on the underlying terrain, with an aircraft. These results are of a similar order of magnitude to the averages in this study. Haack et al. (2014) reported mean dissipation rates between $2 \times 10^{-2}$ and $5 \times 10^{-3} \mathrm{~W} \mathrm{~kg}^{-1}$ for the altitude range 7 to $26.5 \mathrm{~km}$, using a different retrieval and potentially including wake effects.

\section{Conclusions}

In this paper, high-resolution turbulence observations with LITOS are complemented by model simulations with WRF to study the relation between turbulence, waves, and background conditions. Three flights, for which in each case data from two wind sensors are available, are selected. This allows high-quality assurance. Furthermore, any data that are possibly influenced by the balloon's wake have been removed for this study.

Enhanced energy dissipation rates were observed where pronounced instabilities were detected by the radiosonde. Moreover, measured shear instabilities and associated enhancements in dissipation on scales resolved by WRF also coincide with enlarged model turbulent kinetic energy (TKE). For instance, during the BEXUS 12 flight (27 September 2011), a wind reversal was observed which caused a large shear instability (indicated by Richardson numbers smaller than $1 / 4$ ) as well as potential wave filtering. The resulting turbulence was detected by LITOS as a region with large dissipation rates. The model TKE peaks in this region, highlighting the significance of that layer. Similar effects are observed for some strong layers of the 27 March 2014 and 11/12 July 2015 flights. Thus, in these cases the geophysical causes of the observed turbulent layers are clearly visible. The large scale instabilities are resolved by the radiosondes and the model. On the other hand, many other (less intense) turbulent layers observed by LITOS are obviously too thin to be related to the much coarser data of the radiosonde or the WRF results.

Another relation between turbulence detected by LITOS and the presence of wave-like structures in WRF is noted: for the available summer flights at 6 June 2014 (not shown) and 12 July 2015, a drop in turbulence occurrence at approximately $15 \mathrm{~km}$ altitude with hardly any turbulence above was observed. In the associated model simulations, wave sig- 
natures become weaker around $15 \mathrm{~km}$. Altogether, observed dissipation is weaker during lower wave activity (as seen in WRF), and larger where larger wave amplitudes are seen. These findings can be explained by wave saturation, while a change in, for example, static stability is less prominent.

Turbulence has been observed for Richardson numbers below as well as above the critical number of $1 / 4$, partly even for values much larger than 1 . Such a violation of the classical theory by Miles (1961) and Howard (1961) has already been described by several researchers, e.g. Achatz (2005); Galperin et al. (2007); Balsley et al. (2008). Hines (1988) recognised the limitation of considering only vertical instability (as done when using the Richardson number) and proposed a concept of slantwise instabilities as created by gravity waves. He showed that turbulence is more likely to de- velop via slanted instability compared to vertical instability. Thus turbulence for $R i>1 / 4$ is comprehensible.

The results are based on the limited data set from a few flights. More flights at selected meteorological situations are planned to further study the relation between waves and turbulence. A redesign of the instrumental set-up shall eliminate the wake effects of balloon and ropes. Moreover, a direct measurement of gravity wave activity in combination to the turbulence observations is preferable.

Data availability. The data used in this study are available on request to Michael Gerding (gerding@iap-kborn.de). 
Appendix A: Derivation of the constant $c_{l_{0}}$ in Eq. (1)

To retrieve energy dissipation rates from observed spectra, the relation (Eq. 1) between inner scale $l_{0}$ and dissipation rate $\varepsilon, \varepsilon=c_{l_{0}}^{4} \nu^{3} / l_{0}^{4}$, and especially the value of the constant $c_{l_{0}}$ is important. To obtain correct values, care has to be taken as which component(s) of the spectral tensor are observed. In the following, the derivation of the constant $c_{l_{0}}$ is summarised.

In the inertial subrange, the longitudinal component, transversal component, and trace of the structure function tensor for velocity fluctuations have the form

$D_{x x}(r)=C_{x x} r^{2 / 3}$,

where $x x$ is a placeholder for rr (longitudinal), tt (transversal), or $i i$ (trace), and the structure constant has the form $C_{x x}=b_{x x} a_{v}^{2} \varepsilon^{2 / 3}$ with $b_{\mathrm{rr}}=1, b_{\mathrm{tt}}=\frac{4}{3}, b_{i i}=b_{\mathrm{rr}}+2 b_{\mathrm{tt}}=\frac{11}{3}$ (Tatarskii, 1971, p. 54ff) and the empirical constant $a_{v}^{2}=2.0$ (e.g. Pope, 2000, p. 193f). In the viscous subrange, the structure function is

$D_{x x}(r)=\widetilde{C}_{x x} r^{2}$,

with $\widetilde{C}_{x x}=c_{x x} \frac{\varepsilon}{v}$ and the factors $c_{\mathrm{rr}}=\frac{1}{15}, c_{\mathrm{tt}}=\frac{2}{15}, c_{i i}=$ $c_{\mathrm{rr}}+2 c_{\mathrm{tt}}=\frac{1}{3}$ (Tatarskii, 1971, p. 49).

Based on Heisenberg (1948, Eq. 28), Lübken and Hillert (1992, Eq. 4) gave a form of the temporal spectrum in the inertial and viscous subranges, which reads, for velocity fluctuations,

$W(\omega)=\frac{\Gamma\left(\frac{5}{3}\right) \sin \left(\frac{\pi}{3}\right)}{2 \pi u_{\mathrm{b}}} C_{x x} \frac{\left(\omega / u_{\mathrm{b}}\right)^{-5 / 3}}{\left(1+\left(\frac{\omega / u_{\mathrm{b}}}{k_{0}}\right)^{8 / 3}\right)^{2}}$,

where $u_{\mathrm{b}}$ is the ascent velocity of the balloon, $\Gamma(z):=$ $\int_{0}^{\infty} t^{z-1} \mathrm{e}^{-t} \mathrm{~d} t$ is the gamma function, and $k_{0}$ denotes the breakpoint between inertial and viscous subrange. The normalisation is obtained by considering the limit $k \ll k_{0}$ for the inertial subrange. Using the relation $\Phi(k)=-\frac{u_{\mathrm{b}}^{2}}{2 \pi k} \frac{\mathrm{d} W}{\mathrm{~d} \omega}\left(k u_{\mathrm{b}}\right)$ between temporal and spatial spectrum (Tatarskii, 1971, Eq. 6.14), the corresponding three-dimensional spectrum is

$$
\begin{aligned}
& \Phi_{x x}(k)= \\
& \frac{1}{6 \pi} \frac{\Gamma\left(\frac{5}{3}\right) \sin \left(\frac{\pi}{3}\right)}{2 \pi} C_{x x} k^{-11 / 3} \frac{5+21\left(\frac{k}{k_{0}}\right)^{8 / 3}}{\left(1+\left(\frac{k}{k_{0}}\right)^{8 / 3}\right)^{3}} .
\end{aligned}
$$

The constant $c_{l_{0}}$ in Eq. (1) can be computed from the condition of the structure function at the origin

$$
\frac{\mathrm{d}^{2} D_{x x}}{\mathrm{~d} r^{2}}(0)=\frac{8 \pi}{3} \int_{0}^{\infty} \Phi_{x x}(k) k^{4} \mathrm{~d} k
$$

(Tatarskii, 1971, p. 49f). Inserting the structure function (Eq. A2) and the spectrum (Eq. A4) into condition (Eq. A5), integrating and solving for $1 / k_{0}$ yields

$$
\begin{aligned}
l_{0} & =\frac{2 \pi}{k_{0}} \\
& =\underbrace{2 \pi\left(\frac{3}{16} \Gamma(5 / 3) \sin (\pi / 3) \frac{b_{x x}}{c_{x x}} a_{\mathrm{v}}^{2}\right)^{3 / 4}}_{=c_{l_{0}}}\left(\frac{v^{3}}{\varepsilon}\right)^{1 / 4} .
\end{aligned}
$$

CTA wire probes are sensitive perpendicular to the wire axis but insensitive parallel to the wire axis. For the earlier flights, the wires of the CTA sensors were oriented vertically so that they are sensitive in both horizontal directions and insensitive in the vertical direction; i.e. for an ascending balloon both transversal components are measured. Thus $b_{x x}=$ $4 / 3+4 / 3=8 / 3$ and $c_{x x}=2 / 15+2 / 15=4 / 15$, which leads to $c_{l_{0}}=14.1$. For the flight at 12 July 2015, one sensor with the wire oriented horizontally was flown, which is sensitive in the vertical and one horizontal direction yet insensitive in the other horizontal direction (parallel to the wire). In this case $b_{x x}=1+4 / 3=7 / 3$ and $c_{x x}=1 / 15+2 / 15=3 / 15$ so that $c_{l_{0}}=15.8$.

Haack et al. (2014, Sect. 4) used different components of the structure function constant yielding $c_{l_{0}}=5$.7. Since in Eq. (1) the constant occurs with $c_{l_{0}}^{4}$, this results in a difference in $\varepsilon$ of a factor of $\sim 50$ for the same $l_{0}$. 
Competing interests. The authors declare that they have no conflict of interest.

Acknowledgements. The BEXUS programme was financed by the German Aerospace Center (DLR) and the Swedish National Space Board (SNSB). We are grateful for the support from the International Leibniz Graduate School for Gravity Waves and Turbulence in the Atmosphere and Ocean (ILWAO) funded by the Leibniz Association (WGL). This study was partly funded by the German Federal Ministry for Education and Research (BMBF) research initiative "Role of the Middle Atmosphere In Climate" (ROMIC) under project numbers 01LG1206A and 01LG1218A (METROSI), and by the German Research Foundation (DFG) under project numbers LU 1174 (PACOG) and FOR 1898 (MS-GWaves). We thank Wayne K. Hocking and two anonymous reviewers for their valuable comments leading to the improvement of this article. The publication of this article was funded by the Open Access Fund of the Leibniz Association.

Edited by: Peter Haynes

Reviewed by: Wayne K. Hocking and two anonymous referees

\section{References}

Achatz, U.: On the role of optimal perturbations in the instability of monochromatic gravity waves, Phys. Fluids, 17, 094107, https://doi.org/10.1063/1.2046709, 2005.

Andreassen, O., Wasberg, C. E., Fritts, D. C., and Isler, J. R.: Gravity wave breaking in two and three dimensions: 1 . Model description and comparison of two-dimensional evolutions, J. Geophys. Res., 99, 8095-8108, https://doi.org/10.1029/93JD03435, 1994.

Balsley, B. B., Svensson, G., and Tjernström, M.: On the Scale-dependence of the Gradient Richardson Number in the Residual Layer, Bound.-Lay. Meteorol., 127, 57-72, https://doi.org/10.1007/s10546-007-9251-0, 2008.

Barat, J.: Some characteristics of clear-air turbulence in the middle stratosphere, J. Atmos. Sci., 39, 2553-2564, https://doi.org/10.1175/15200469(1982)039<2553:SCOCAT>2.0.CO;2, 1982.

Barat, J., Cot, C., and Sidi, C.: On the measurement of turbulence dissipation rate from rising balloons, J. Atmos. Ocean. Tech., 1, 270-275, 1984.

Birner, T.: Fine-scale structure of the extratropical tropopause region, J. Geophys. Res., 111, D04104, https://doi.org/10.1029/2005JD006301, 2006.

Birner, T., Dörnbrack, A., and Schumann, U.: How sharp is the tropopause at midlatitudes?, Geophys. Res. Lett., 29, 45-1-454, https://doi.org/10.1029/2002GL015142, 2002.

Brasseur, G. and Solomon, S.: Aeronomy of the middle atmosphere: chemistry and physics of the stratosphere and mesosphere, 2nd Edn., Atmospheric sciences library, Reidel, Dordrecht, 1986.

Chen, F. and Dudhia, J.: Coupling an Advanced Land SurfaceHydrology Model with the Penn State-NCAR MM5 Modeling System, Part I: Model Implementation and Sensitivity, Mon. Weather Rev., 129, 569-585, https://doi.org/10.1175/15200493(2001)129<0569:CAALSH>2.0.CO;2, 2001.
Cho, J. Y. N., Newell, R. E., Anderson, B. E., Barrick, J. D. W., and Thornhill, K. L.: Characterizations of tropospheric turbulence and stability layers from aircraft observations, J. Geophys. Res., 108, 8784, https://doi.org/10.1029/2002JD002820, 2003.

Chou, M. D. and Suarez, M. J.: An efficient thermal infrared radiation parameterization for use in general circulation models, NASA Tech. Memo., 104606, 85 pp., 1994.

Clayson, C. A. and Kantha, L.: On Turbulence and Mixing in the Free Atmosphere Inferred from High-Resolution Soundings, J. Atmos. Ocean. Tech., 25, 833-852, https://doi.org/10.1175/2007JTECHA992.1, 2008.

Cot, C. and Barat, J.: Wave-turbulence interaction in the stratosphere: A case study, J. Geophys. Res., 91, 2749-2756, https://doi.org/10.1029/JD091iD02p02749, 1986.

Dalaudier, F., Sidi, C., Crochet, M., and Vernin, J.: Direct Evidence of "Sheets" in the Atmospheric Temperature Field, J. Atmos. Sci., 51, 237-248, https://doi.org/10.1175/15200469(1994)051<0237:DEOITA>2.0.CO;2, 1994.

Ehard, B., Achtert, P., Dörnbrack, A., Gisinger, S., Gumbel, J., Khaplanov, M., Rapp, M., and Wagner, J. S.: Combination of lidar and model data for studying deep gravity wave propagation, Mon. Weather Rev., 144, 77-98, https://doi.org/10.1175/MWRD-14-00405.1, 2016.

Franke, P. M. and Collins, R. L.: Evidence of gravity wave breaking in lidar data from the mesopause region, Geophys. Res. Lett., 30, https://doi.org/10.1029/2001GL014477, 1155, 2003.

Fritts, D. C. and Alexander, M. J.: Gravity wave dynamics and effects in the middle atmosphere, Rev. Geophys., 41, 1003, https://doi.org/10.1029/2001RG000106, 2003.

Fritts, D. C. and Wang, L.: Gravity Wave-Fine Structure Interactions, Part II: Energy Dissipation Evolutions, Statistics, and Implications, J. Atmos. Sci., 70, 3735-3755, https://doi.org/10.1175/JAS-D-13-059.1, 2013.

Fritts, D. C., Wang, L., Geller, M. A., Lawrence, D. A., Werne, J., and Balsley, B. B.: Numerical Modeling of Multiscale Dynamics at a High Reynolds Number: Instabilities, Turbulence, and an Assessment of Ozmidov and Thorpe Scales, J. Atmos. Sci., 73, 555-578, https://doi.org/10.1175/JAS-D-14-0343.1, 2016.

Galperin, B., Sukoriansky, S., and Anderson, P. S.: On the critical Richardson number in stably stratified turbulence, Atmos. Sci. Lett., 8, 65-69, https://doi.org/10.1002/asl.153, 2007.

Gavrilov, N. M.: Estimates of turbulent diffusivities and energy dissipation rates from satellite measurements of spectra of stratospheric refractivity perturbations, Atmos. Chem. Phys., 13, 12107-12116, https://doi.org/10.5194/acp-13-12107-2013, 2013.

Haack, A., Gerding, M., and Lübken, F.-J.: Characteristics of stratospheric turbulent layers measured by LITOS and their relation to the Richardson number, J. Geophys. Res., 119, 10605-10618, https://doi.org/10.1002/2013JD021008, 2014.

Hauf, T.: Aircraft Observation of Convection Waves over Southern Germany - A Case Study, Mon. Weather Rev., 121, 3282-3290, https://doi.org/10.1175/15200493(1993)121<3282:AOOCWO>2.0.CO;2, 1993.

Heisenberg, W.: Zur statistischen Theorie der Turbulenz, Z. Phys., 124, 628-657, https://doi.org/10.1007/BF01668899, 1948.

Hines, C. O.: Generation of Turbulence by Atmospheric Gravity Waves, J. Atmos. Sci., 
45, 1269-1278, https://doi.org/10.1175/15200469(1988)045<1269:GOTBAG>2.0.CO;2, 1988.

Hines, C. O.: The Saturation of Gravity Waves in the Middle Atmosphere, Part I: Critique of Linear-Instability Theory, J. Atmos. Sci., 48, 1348-1360, https://doi.org/10.1175/15200469(1991)048<1348:TSOGWI>2.0.CO;2, 1991.

Hocking, W. K.: A review of Mesosphere-StratosphereTroposphere (MST) radar developments and studies, circa 1997-2008, J. Atmos. Sol.-Terr. Phy., 73, 848-882, https://doi.org/10.1016/j.jastp.2010.12.009, 2011.

Hodges, R. R.: Generation of turbulence in the upper atmosphere by internal gravity waves, J. Geophys. Res., 72, 3455-3458, https://doi.org/10.1029/JZ072i013p03455, 1967.

Hong, S.-Y. and Lim, J.-O. J.: The WRF single-moment 6-class microphysics scheme (WSM6), J. Korean Meteor. Soc., 42, 129151,2006

Howard, L. N.: Note on a paper of John W. Miles, J. Fluid Mech., 10, 509-512, https://doi.org/10.1017/S0022112061000317, 1961.

Kain, J. S. and Fritsch, J. M.: A One-Dimensional Entraining/Detraining Plume Model and Its Application in Convective Parameterization, J. Atmos. Sci., 47, 2784-2802, https://doi.org/10.1175/15200469(1990)047<2784:AODEPM>2.0.CO;2, 1990.

Klemp, J. B., Dudhia, J., and Hassiotis, A. D.: An Upper Gravity-Wave Absorbing Layer for NWP Applications, Mon. Weather Rev., 136, 3987-4004, https://doi.org/10.1175/2008MWR2596.1, 2008.

Lilly, D. K., Waco, D. E., and Adelfang, S. I.: Stratospheric Mixing Estimated from High-Altitude Turbulence Measurements, J. Appl. Meteor., 13, 488-493, https://doi.org/10.1175/15200450(1974)013<0488:SMEFHA>2.0.CO;2, 1974.

Lindzen, R. S.: Turbulence and stress owing to gravity wave and tidal breakdown, J. Geophys. Res., 86, 9707-9714, https://doi.org/10.1029/JC086iC10p09707, 1981.

Lübken, F.-J. and Hillert, W.: Measurements of turbulent energy dissipation rates applying spectral models, in: Coupling Processes in the Lower and Middle Atmosphere, NATO Advanced Research Workshop, Kluwer Press, Loen, Norway, 345-351, 1992.

Luce, H., Fukao, S., Dalaudier, F., and Crochet, M.: Strong Mixing Events Observed near the Tropopause with the MU Radar and High-Resolution Balloon Techniques, J. Atmos. Sci., 59, 2885-2896, https://doi.org/10.1175/15200469(2002)059<2885:SMEONT>2.0.CO;2, 2002.

Miles, J. W.: On the stability of heterogeneous shear flows, J. Fluid Mech., 10, 496-508, https://doi.org/10.1017/S0022112061000305, 1961.

Mlawer, E. J., Taubman, S. J., Brown, P. D., Iacono, M. J., and Clough, S. A.: Radiative transfer for inhomogeneous atmospheres: RRTM, a validated correlated-k model for the longwave, J. Geophys. Res., 102, 16663-16682, https://doi.org/10.1029/97JD00237, 1997.

Nakanishi, M. and Niino, H.: Development of an Improved Turbulence Closure Model for the Atmospheric Boundary Layer, J. Meteor. Soc. Japan, 87, 895-912, http://ci.nii.ac.jp/naid/ 110007465760/en/, 2009.
Nappo, C. J.: An Introduction to Atmospheric Gravity Waves, International Geophysics Series, Academic Press, San Diego, Vol. 85, 2002.

Osman, M., Hocking, W., and Tarasick, D.: Parameterization of large-scale turbulent diffusion in the presence of both well-mixed and weakly mixed patchy layers, J. Atmos. Sol.-Terr. Phy., 143144, 14-36, https://doi.org/10.1016/j.jastp.2016.02.025, 2016.

Paoli, R., Thouron, O., Escobar, J., Picot, J., and Cariolle, D.: High-resolution large-eddy simulations of stably stratified flows: application to subkilometer-scale turbulence in the upper troposphere-lower stratosphere, Atmos. Chem. Phys., 14, 50375055, https://doi.org/10.5194/acp-14-5037-2014, 2014.

Pavelin, E., Whiteway, J. A., and Vaughan, G.: Observation of gravity wave generation and breaking in the lowermost stratosphere, J. Geophys. Res., 106, 5173-5179, https://doi.org/10.1029/2000JD900480, 2001.

Pope, S. B.: Turbulent Flows, Cambridge University Press, Cambridge, 2000.

Schneider, A., Gerding, M., and Lübken, F.-J.: Comparing turbulent parameters obtained from LITOS and radiosonde measurements, Atmos. Chem. Phys., 15, 2159-2166, https://doi.org/10.5194/acp-15-2159-2015, 2015.

Skamarock, W. C., Klemp, J. B., Dudhia, J., Gill, D. O., Barker, D. M., Duda, M. G., Huang, X.-Y., Wang, W., and Powers, J. G.: A description of the Advanced Research WRF Version 3, NCAR technical note, Mesoscale and Microscale Meteorology Division, National Center for Atmospheric Research, Boulder, Colorado, USA, http://www2.mmm.ucar.edu/wrf/users/ docs/arw_v3.pdf, 2008.

Tatarskii, V. I.: The effects of the turbulent atmosphere on wave propagation, Israel Program for Scientific Translations, Jerusalem, translated from Russian, 1971.

Theuerkauf, A., Gerding, M., and Lübken, F.-J.: LITOS - a new balloon-borne instrument for fine-scale turbulence soundings in the stratosphere, Atmos. Meas. Tech., 4, 55-66, https://doi.org/10.5194/amt-4-55-2011, 2011.

Wilson, R.: Turbulent diffusivity in the free atmosphere inferred from MST radar measurements: a review, Ann. Geophys., 22, 3869-3887, https://doi.org/10.5194/angeo-22-3869-2004, 2004.

Wilson, R., Luce, H., Hashiguchi, H., Nishi, N., and Yabuki, Y.: Energetics of persistent turbulent layers underneath mid-level clouds estimated from concurrent radar and radiosonde data, J. Atmos. Sol.-Terr. Phy., 118, 78-89, https://doi.org/10.1016/j.jastp.2014.01.005, 2014.

Worthington, R. M.: Tropopausal turbulence caused by the breaking of mountain waves, J. Atmos. Sol.-Terr. Phys., 60, 1543-1547, https://doi.org/10.1016/S1364-6826(98)00105-9, 1998.

Yamanaka, M. D., Tanaka, H., Hirosawa, H., Matsuzaka, Y., Yamagami, T., and Nishimura, J.: Measurement of Stratospheric Turbulence by Balloon-Borne "Glow-Discharge" Anemometer, J. Meteor. Soc. Japan Ser. II, 63, 483-489, https://www.jstage. jst.go.jp/article/jmsj1965/63/3/63_3_483/_article, 1985. 